\title{
Design of a paediatric rate of reading test chart
}

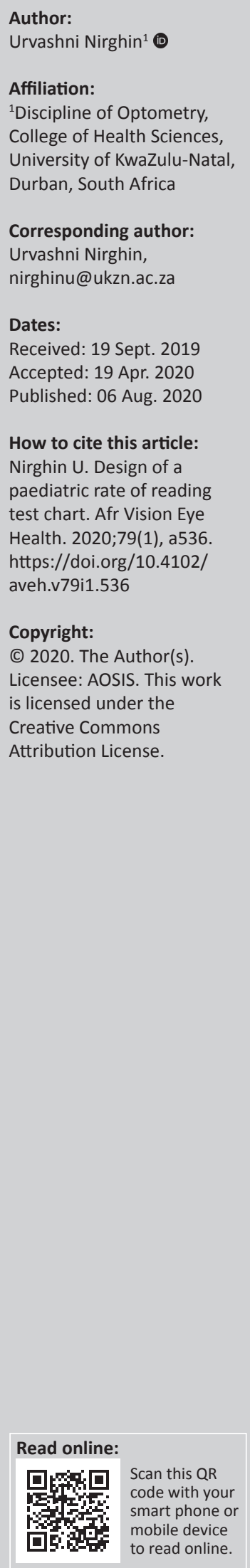

Background: Reading rate reflects the quality of reading performance, especially in children, not typically measured during routine eye examinations. There is currently no reading rate chart with optometric notations made specifically for children with normal vision and low vision.

Aim: To design a chart with optometric notations to measure reading rates in normally sighted and low-vision children.

Setting: The study was conducted in an assigned room of a selected school with fluorescent lighting.

Methods: Ten words were randomly arranged in each of the 10 rows of the chart. Two font versions were printed in black ink on white cardboards. Reliability and validity of the chart was established with 100 normally sighted children. Data were analysed using paired $t$-tests, Pearson's correlation and the Bland and Altman method.

Results: Six versions each in Arial and Times New Roman fonts were designed, with equivalent Snellen acuity levels, with each version having four acuity notations. Reliability results were $p=0.29$ and $R^{2}=0.95$, with the Bland and Altman method revealing a mean difference of -0.58 correct words read per minute (cwpm) with confidence limits of +10.07 and -11.23 cwpm. Validity determined with the Wilkins chart and the new chart were $p=0.01$ and $R^{2}=0.99$, with the Bland and Altman method showing a mean difference of $+0.90 \mathrm{cwpm}$ with confidence limits of +6.33 cwpm and -4.53 cwpm.

Conclusions: This chart is a reliable and valid tool and can be used for assessing reading rates of normally sighted and low-vision children.

Keywords: reading rate; reading performance; reading chart; low vision; children.

\section{Introduction}

School children spend six hours or more per day at school, approximately half of which is spent in reading books. ${ }^{1}$ Reduced vision may limit reading in children, which can negatively affect their learning ${ }^{2,3}$ Fluency is an important indicator of reading and is best evaluated by reading rate ${ }^{4}$ which is calculated as the number of correct words read per minute (cwpm). ${ }^{5,6}$ Reading rate is affected by several visual factors such as acuity reserve, letter contrast, contrast reserve, field of view (perceptual span), print size and perceptual distortions. ${ }^{2,5,7,8}$ Reading rate reflects the quality of reading and influences the functional efficiency of those whose vocation requires accurate reading. However, reading rate is not typically measured during routine optometric examinations. During examination of low-vision patients, reading performance is not commonly evaluated except for a brief assessment of threshold print size and fluency. ${ }^{9}$ It is imperative that optometric examinations incorporate reading rate assessments, especially for school children. A measure of reading rate not only assesses the threshold print size but also the speed and accuracy. Appropriate test charts are therefore needed to evaluate reading performance in both normal and partially sighted children.

According to Wilkins et al., conventional reading tests are designed for educational use and are not suitable for assessing the effects of any optometric intervention. ${ }^{5}$ This is because (1) they assess the linguistic and semantic aspects of reading at least as much as the visual; (2) the test items typically increase in complexity until the reader fails, and the visual complexity of the material usually covaries with linguistic complexity; (3) performance is usually limited by the reader's vocabulary, and adults therefore score at or near the test ceiling; (4) children with poor reading ability are aware of their failures and are often embarrassed by this. Charts designed with passages of text are often used by optometrists for routine eye examinations when assessing reading performance as well as when prescribing spectacles and magnifiers for reading at near distance. The Bailey-Lovie ${ }^{10}$ and Minnesota Low Vision Reading Test (MNREAD) charts ${ }^{2,11}$ are commonly used to measure reading rate; however, these are not suitable for young children with limited vocabulary. ${ }^{5}$ 
Wilkins et al. designed a reading rate test (RRT) chart (the rate of reading test) that is currently used by optometrists for reading rate assessment. ${ }^{5}$ It has been used in the assessment of vision-related reading rates such as the prolonged use of coloured overlays for classroom reading ${ }^{12}$ and the effect of overlays on reading in albinism. ${ }^{13}$ Whilst the chart is useful for evaluation of reading rate, from an optometric point of view, it has two major limitations. Firstly, the chart does not take the visual acuity (VA) of the reader into consideration, as the acuity notations and values of the test letters are not indicated in the chart or on the recording sheet. As VA influences reading performance, it is an important element in reading performance assessment, and hence the size and notation of the paragraph being used for assessment should be indicated. Secondly, the size of letters needed to assess children with low vision is not adequately represented on the chart. The aim of this study therefore was to design a paediatric rate of reading (PRR) test chart with appropriate VA notations and print sizes that could be used for normally sighted and low-vision primary school children, especially those aged 6-12 years.

\section{Methods}

This study followed the tenets of the Declaration of Helsinki with informed consent being obtained from the parents of the participants explaining the nature and possible consequences of the study. Approval to conduct this study was obtained from the Research and Ethics Committee of the School of Health Sciences, University of KwaZulu-Natal. Assents were completed by all participants. All the guidelines of the committee were adhered to before, during and after the research study.

\section{Design of paediatric rate of reading chart}

A list of all primary schools $(N=411)$ in South Africa, where English was offered as first or second language, was obtained from the Department of Education. A systematic random sampling method was used to select five schools from the list. English reading text books used by first-grade students of those schools were obtained and all words in the books $(N=285)$ were recorded. To maintain an average word difficulty, 10 words containing three or four letters were randomly selected and used in the design of the chart. Words with less or more than three to four letters and those containing special characters, punctuations or names were excluded. Ten commonly used words that were considered to be appropriate for the design of the chart were chosen. These words were used in each row (line) but in a different random order, as recommended by Bailey-Lovie ${ }^{10}$ and Ahn and Legge. ${ }^{2}$ The random arrangement was achieved by assigning numbers to each of the 10 words, and from the list of random numbers, a table was generated with the numbers subsequently being replaced by the corresponding words for placement on the chart. Although Ferraro and Ferraro ${ }^{14}$ have suggested 150 words per paragraph and Wilkins et al. ${ }^{5}$ used the same number of words, the current design used 100 words per paragraph. This number of words was chosen because the chart was designed specifically for children, including those with low vision.

The words were typed on a personal computer and a graphic artist assisted in scaling the prints to the required sizes (heights) (1.45 millimetre [mm], $1.75 \mathrm{~mm}, 2.33 \mathrm{~mm}$, $2.91 \mathrm{~mm}, 4.65 \mathrm{~mm}$ and $5.82 \mathrm{~mm}$ ) corresponding to the six VA values of $1 \mathrm{M}, 1.25 \mathrm{M}, 1.6 \mathrm{M}, 2.0 \mathrm{M}, 3.2 \mathrm{M}$ and $4.0 \mathrm{M}$ $(6 / 15,6 / 18,6 / 24,6 / 30,6 / 48$ and 6/60). In addition, each version had four VA notations: Metre (M), Snellen (Feet), Snellen (Meter) and Logarithm of Minimum Angle of Resolution (LogMAR). The inter-word and inter-row spaces were equal to those in the computer-generated print, and all words were printed in lower case. Each chart was of $29.7 \times$ 21 centimetre $(\mathrm{cm})$ (approximately A4) in size and comprised a white cardboard with the words printed in black ink. The charts were named A, B, C, D, E and F, each containing words in one of the six different acuity levels, with all versions printed in Times New Roman and Arial fonts, as shown in Figure 1 for Chart D.

\section{Pre-test chart}

The pre-test chart, for each of the two font versions (Times New Roman and Arial) comprised all 10 words used in the design of the chart, but in large font $(5.82 \mathrm{~mm})$, they were arranged in two columns of five words each. The pre-test charts were printed on an A4 size sheet (Figure 2).

\section{Version D}

\begin{tabular}{ccc}
\multicolumn{3}{c}{ Arial Font } \\
$2.0 \mathrm{M} \quad(20 / 100) \quad(6 / 30) \quad(0.7$ LogMAR $)$
\end{tabular}

said can cat play see you yes help the look help play said you yes look the can cat see can see help said cat you play yes look the see you look can said play cat the help yes cat help said yes the can see you play look play see look cat said the you can yes help you can play cat see said look the help yes the see cat you said play help can yes look play cat can yes you look the said help see the you look help can yes play see cat said

FIGURE 1: Version D of the paediatric rate of reading chart in Arial font. 


\section{Pre-test chart}

\section{Time New Roman Font}

\section{the}

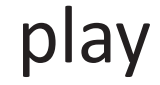

cat

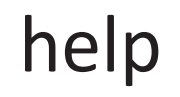

look

you

\section{said}

can

\section{see}

\section{yes}

FIGURE 2: The paediatric rate of reading pre-test chart in Times New Roman font.

\section{Scoring sheet}

The scoring sheet contains the same number of words and similar layout as each version (A, B, C, D, E and F) of the chart (Figure 3). Each row of the paragraph of the sheet contains cumulative word count in the margin from 10 to 100 as recommended by Ferraro and Ferraro. ${ }^{14}$ This would enable the examiner to make a quick reference to the number of words read by the subject. Large inter-row spaces are provided below each row of the sheet to record various reading errors made during testing. Words not in the chart but added by the reader were to be represented by an underscore (_) and words omitted were circled. Spaces for demographic and other relevant details are provided.

\section{Reliability and validity of the paediatric rate of reading chart}

Developing a new test chart requires a rigorous process to reduce possible bias. Two hundred children of both genders from two primary schools were recruited to serve as subjects in establishing the reliability and validity of the chart. These children underwent a visual screening, which included near VA (logMAR VA) and internal and external ocular health evaluation. The inclusion criteria were near VA of

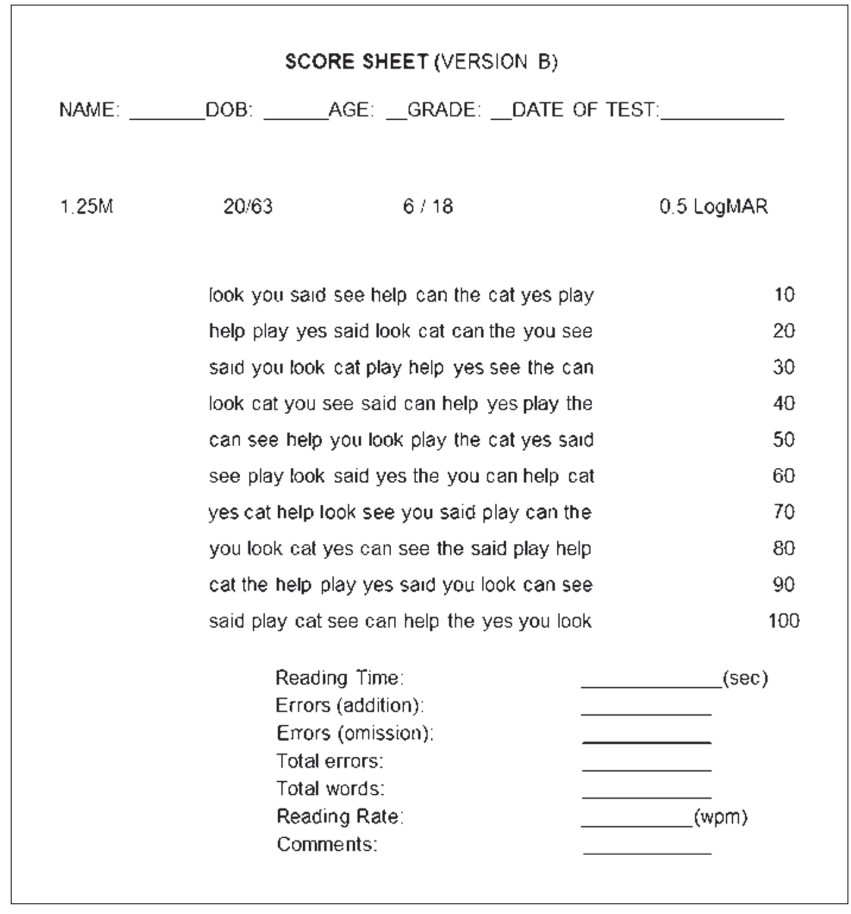

sec, second; wpm, words per minute; DOB, date of birth.

FIGURE 3: Version B score sheet of the paediatric rate of reading chart.

$1 \mathrm{M}(6 / 15)$ or better and an absence of any visual and ocular anomaly or pathology. The PRR pre-test chart was also administered to them. The first 200 children who met the inclusion criteria were included in this part of the study. One hundred of these acted as participants in the establishment of the reliability and the other 100 took part in the validity establishment. For reliability and validity, the $1 \mathrm{M}$ and $2 \mathrm{M}$ Arial font versions of the PRR chart were used. Only normally sighted children, aged 9-12 years, were considered to test for reliability and validity because it was reckoned that they would be able to decode words rapidly, ${ }^{15}$ and hence read rapidly, reducing testing period and ensuring minimum disruption in their academic programmes.

Reliability was established by comparing test (R1) and retest (R2) reading rates (cwpm) obtained from 100 children over 1-week interval. The equipment and materials used included the PRR chart, a stopwatch, PRR record score sheet and a reading stand. The measurements were performed in a classroom with good illumination provided by an overhead fluorescent light and a distant window. The test procedure was explained to each child and he or she was told not to use fingers to aid the reading process. The $1 \mathrm{M}(6 / 15)$ version of PRR chart was placed on a reading stand at a distance of $40 \mathrm{~cm}$ from the child's spectacle plane. The child was asked to read words aloud (binocularly) as rapidly as possible when the examiner says ' $g o^{\prime}$ ', and to stop when the examiner says 'stop'. The time between 'go' and 'stop' was measured with a stop watch. At exactly 1 minute or as soon as the child had read all the words, the watch was stopped and the number of words read by the child was noted on the score sheet. In addition, any error, such as 
addition or omission of words, was documented on the score sheet and deducted from the total words read, and the reading rate calculated. In a few cases where a child finished reading the passage in less than $1 \mathrm{~min}$, the reading rates were calculated as recommended in the Wilkins RRT manual:

Reading rate $=\frac{60 \times(\text { Total number of words correctly read })}{(\text { Total time taken in seconds })}$

[Eqn 1]

The reading rate of the same 100 children was retested one week later and the results were documented on the score sheet and a data table.

The validity data were collected approximately one week after the reliability data using the second set of 100 children. Data obtained from a 2 M (20/30) Arial version of PRR chart and a similar version of the Wilkins ${ }^{5}$ chart were compared in establishing the validity of the chart. To minimise bias during this aspect of data collection, in the first week, data were collected for 50 children first with the PRR chart and then with the Wilkins chart following week, data were collected for the remaining 50 children, firstly with the Wilkins chart and subsequently with the PRR chart.

Data were analysed with descriptive statistics and Pearson's correlation using Statistical Package of Social Sciences (SPSS) version 18. The Bland and Altman plot ${ }^{15}$ was also used to assess the degree of agreement between two sets of reading rate across participants.

\section{Ethical considerations}

Ethical approval to conduct this study was obtained from the Research and Ethics Committee of the School of Health Sciences, University of KwaZulu-Natal (Approval Number HSS/0525/2009).

\section{Results}

\section{Reliability results}

The children's age ranged from 9 to 12 years (mean $=10.32 \pm$ 0.95 years). The sample included $42 \%$ males and $58 \%$ females. The mean reading rate values for test (R1) and retest (R2) were $77.6 \mathrm{cwpm} \pm 25.3 \mathrm{cwpm}$ and $78.23 \mathrm{cwpm} \pm 24.7 \mathrm{cwpm}$ respectively. Even though there was no significant difference ( $p=0.287$ ) between R1 and R2, a strong positive correlation $(r=0.98)$ was shown (Figure 4$)$.

The Bland and Altman plot (Figure 5) shows the mean difference (the black solid line) and the upper (red) and lower (green) 95\% limits of agreement. The mean difference was $-0.5819 \mathrm{cwpm}$, whilst the upper and lower limits of agreement were $10.07 \mathrm{cwpm}$ and $-11.23 \mathrm{cwpm}$, respectively. Approximately $95 \%$ of the reading rate differences lie within these limits of agreement.

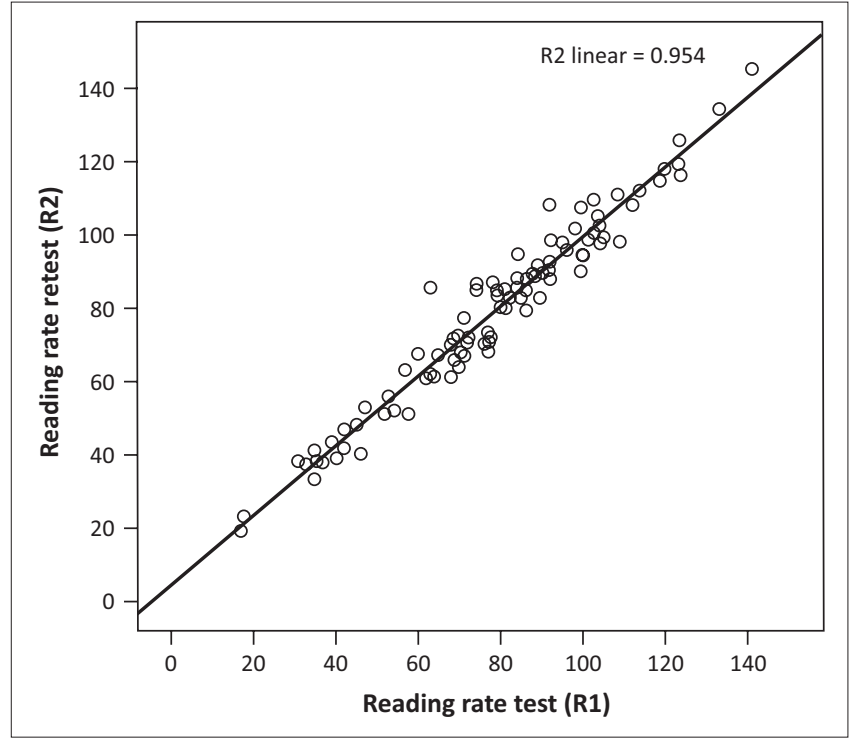

$R 1$, test; R2, retest.

FIGURE 4: Scatter plot showing paediatric rate of reading (PRR) test (R1) and retest (R2) in correct words per minute at first and second testing session, 1 week apart, using the PRR chart. R1 and R2 measurements show a strong correlation $(r=0.98)$

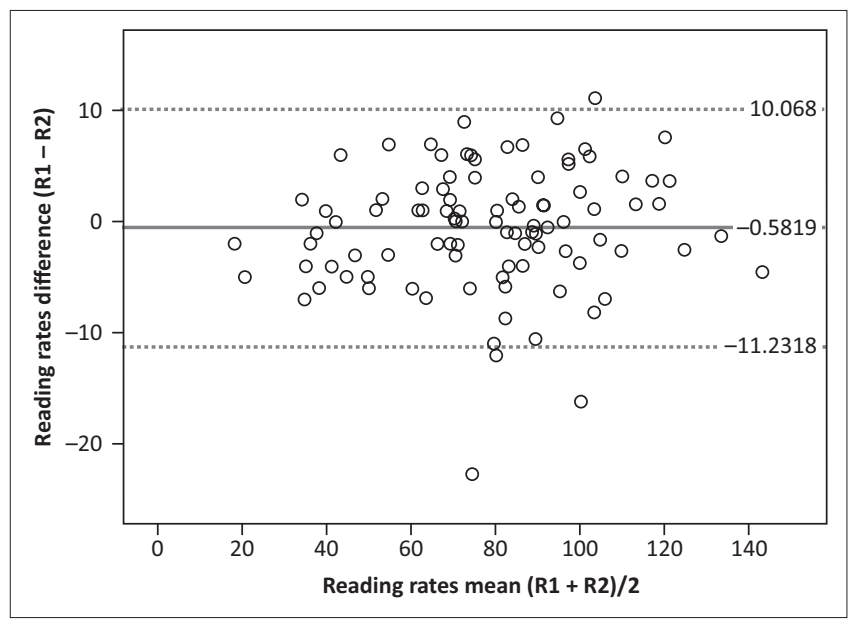

$\mathrm{R} 1$, test; $\mathrm{R} 2$, retest.

FIGURE 5: Differences between reading rate (correct words per minute) test (R1) and retest $(\mathrm{R} 2)$ for individual learners $(N=100)$ obtained with paediatric rate of reading (PRR) chart are plotted against the averages of $R 1$ and $R 2$ reading rates, 1 week apart, according to the Bland and Altman method. The derived 95\% confidence intervals are also shown (dotted lines). The mean test-retest difference is very small $(-0.58)$ and is indicated by a solid black line.

\section{Validity results}

The 100 children's age ranged from 9 to 12 years (mean = $10 \pm 1$ years) and the sample included $39 \%$ males and $61 \%$ females. The reading rate ranged from $51.3 \mathrm{cwpm}$ to $98.5 \mathrm{cwpm}$ (mean of $74.9 \mathrm{cwpm} \pm 23.6 \mathrm{cwpm}$ ) for the PRR chart, and from $52.2 \mathrm{cwpm}$ to $99.5 \mathrm{cwpm}$ (mean of $75.8 \mathrm{cwpm} \pm 23.6 \mathrm{cwpm}$ ) for the Wilkins chart. A strong positive correlation was shown between the reading rates (cwpm) of the PRR and Wilkins tests (Pearson's correlation coefficient, $r=0.993, R^{2}=0.986$ ) (Figure 6).

The Bland and Altman plot (Figure 7) at 95\% confidence limit shows a mean difference of $0.90 \mathrm{cwpm}$ and the confidence limits (upper $=6.33 \mathrm{cwpm}$ and lower $=-4.53 \mathrm{cwpm}$ ). 


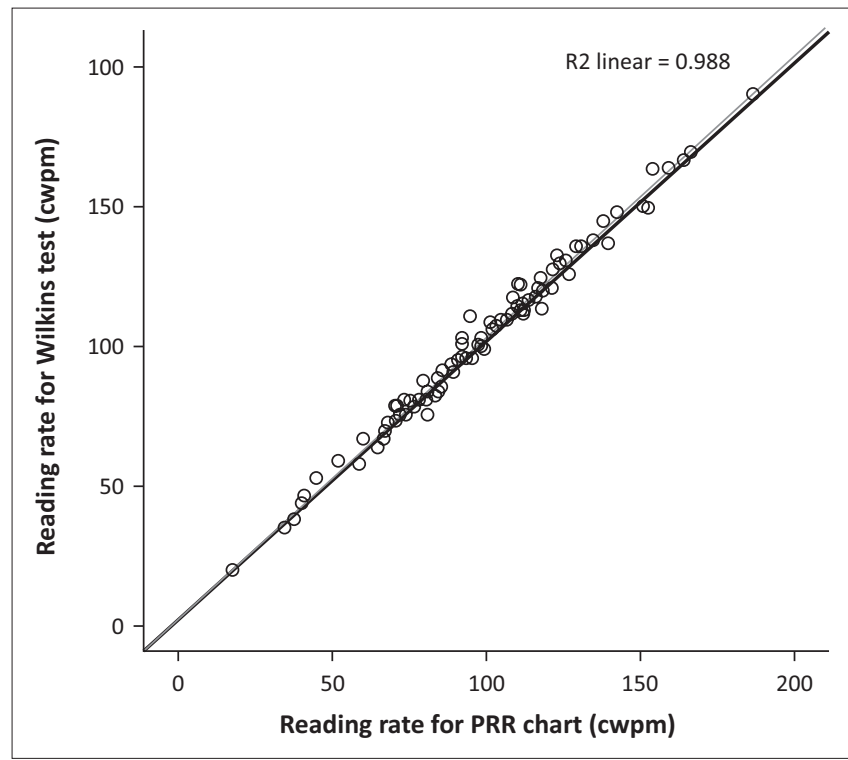

PPR, paediatric rate of reading; cwpm, correct words per minute; R1, test; R2, retest. FIGURE 6: Scatter plot showing reading rate (correct words per minute) test (R1) and retest (R2) with paediatric rate of reading and Wilkins tests. R1 and R2 measurements show a strong correlation $(r=0.99)$.

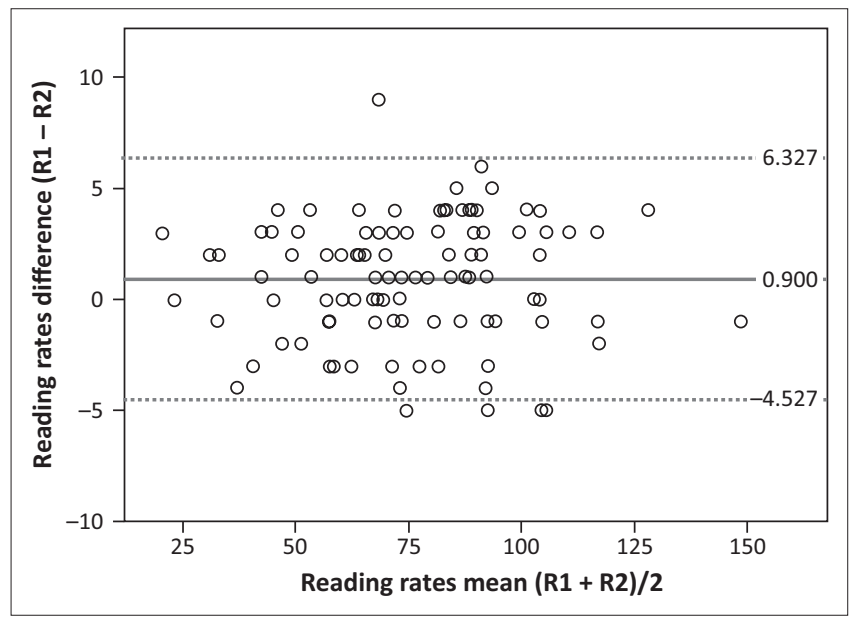

$R 1$, test; R2, retest.

FIGURE 7: Differences between reading rate measurements for individual learners obtained with the Wilkins test and the paediatric rate of reading chart are plotted against the averages of these data according to the Bland and Altman method. The upper and lower confidence intervals are represented by dotted lines.

\section{Discussion}

Reading is an important aspect of a child's developmental milestones and should regularly be evaluated in order to detect anomalies that may hinder reading and learning processes. Visual factors (such as reduced vision because of refractive error and/or ocular pathology, accommodative problems, binocular vision anomalies, ocular motility problems and visual perceptual skills) that may degrade reading performance could be diagnosed, and most could be ameliorated by optometrists. In terms of reading performance, optometrists often focus on establishing threshold print size that a person could achieve with and without spectacles. Reading rate assessment is important during optometric examinations for children with normal and low vision. For the normally sighted children, it is important because it would provide an opportunity for assessing behavioural aspects of reading, spelling and rapid naming processes that could influence reading performance. Although optometrists do not diagnose non-visual causes of poor reading performance, they can refer such cases to appropriate professionals for diagnosis and necessary care. As low vision affects negatively the reading ability, and the goal of most people with the condition is to read at near or distance, it is imperative that aspects of reading such as reading rate be a part of reading assessment for low-vision children. Optometrists play a pivotal role in assessing the visual capabilities of low-vision patients and in determining the most appropriate reading assistance ${ }^{8}$ that could be provided for the patients. The rate of reading should be included in such a reading performance assessment to determine the speed and accuracy of reading. Low vision in children could be improved by using simple low-vision devices, ${ }^{16}$ and the determination of efficacy of such devices must include reading rate assessment. This further justifies the need for appropriate reading performance test charts, such as the RRT chart.

Ideally, for the establishment of near reading rate norms, reading performance should be determined at the level of the patient's best or slightly better near VA. However, for functional purposes, the reading rate of the child should be assessed at the print size that they are expected to see in school. In either case, the appropriate acuity level should be established before the assessment of reading performance and for the future reference purpose; therefore, there is a need to provide acuity notation for each paragraph of reading assessment charts.

Words containing three to five letters were used in the design of the chart as these were considered to be of an average difficulty for children as young as six years old. Also, unconnected words in random orders were used as recommended by other authors. . $, 5,10^{2}$ This type of randomly ordered words reduces the reading speed variability attributable to linguistic factors as well as the syntactic and linguistic properties of the text. ${ }^{2,5}$

The first barrier to reading for most children with low vision is the small print size that could not be seen. ${ }^{17}$ Therefore, to assess their reading performance, appropriate print size should be used. Although reading passages designed for normally sighted children have been used to assess reading performance in low-vision children, ${ }^{18}$ such a chart is not appropriate for many low-vision children, especially those with severe vision loss. Although not indicated on the chart, the largest print size on the Wilkins chart is approximately $2 \mathrm{M}$, which may not be large enough for many low-vision children, even when the reading distance is reduced (relative distance magnification). Several standard charts used for low-vision patients (including children) have acuity values greater than $2 \mathrm{M}$, for example the Bailey-Lovie chart ${ }^{10}$ ranging from $0.25 \mathrm{M}$ to $5 \mathrm{M}$ and the MNREAD ${ }^{2}$ chart has acuity values ranging from $0.16 \mathrm{M}$ to $8 \mathrm{M}$. The present chart 
uses a design of 100 words-per-paragraph as this would reduce testing time, which is necessary when testing children. The maximum print size was limited to $4 \mathrm{M}$ because it was found to be the size that could conveniently fit onto an A4 size cardboard. In order to cater for children who require larger than $4 \mathrm{M}$ print size, the reading distance could be reduced to provide relative distance magnification. The minimum print size (version A) of $1 \mathrm{M}(6 / 15)$ was chosen for the design because it is generally agreed to be the minimum print size needed by the majority of low-vision children for most reading tasks. ${ }^{11,19}$ Also, it is reckoned to be large enough for most normally sighted children. Clinical experience has shown that young children, especially those with low vision, have a low rate of reading. In addition, as print sizes up to $4 \mathrm{M}$ acuity $(5.82 \mathrm{~mm})$ were used in the chart, 150 words (15 words per row or 15 lines per paragraph) would create an unnecessarily large chart.

A wide range of VA values, $1.0 \mathrm{M}(6 / 15)(0.4 \log \mathrm{MAR})$ to $4 \mathrm{M}$ $(6 / 60),(1.0 \log \mathrm{MAR})$, were used in the chart to provide a variety of acuity options that may be necessary for evaluation of reading rate. In addition, four acuity notations commonly used by eye care practitioners (Metre [M], Snellen [ft], Snellen [M] and LogMAR) were provided in each version of the chart. The paragraphs were printed in black on approximately white cardboard to provide maximum contrast. ${ }^{19}$

Pearson's correlation, for both reliability and validity of the PRR test, reveals strong correlation between RRT values, whilst the Bland and Altman plots display excellent reliability and validity. Reliability results show a slight increase in the reading rate mean on retest. Possible explanation for this increase could be because of memorisation of the words used in the test chart, familiarity of the testing procedure as well as the examiner. The impact of memorisation, however, was limited by the design of the test using random placement of words. ${ }^{2,5,10}$ Furthermore, test and retest one week apart does control for memorisation and the learning effect. ${ }^{20}$ Finally, as expected, vocabulary acquisition increases daily, and exposure to other reading material during the course of intersession period may have also resulted in this increase. ${ }^{21}$

\section{Conclusion}

A reliable and valid chart with optometric features has been designed that could be used to assess the reading rate of normally sighted and low-vision children. This test was successfully conducted on low-vision children and the results would follow in a subsequent article. The chart can be used to measure reading rates before and after optometric intervention. In addition, as reading rate is a sensitive measure of reading performance, the PRR chart can be used to develop reading rate norms for children of different age and grade groups to assist in determining reading performance such as speed and accuracy.

\section{Acknowledgements}

The late Prof. O.A. Oduntan served as the supervisor of this study.

\section{Competing interests}

The author has declared that no competing interests exist.

\section{Author's contributions}

I declare that I am the sole author of this research article.

\section{Funding information}

This work was supported and funded by the University of KwaZulu-Natal.

\section{Data availability statement}

Data sharing is not applicable to this article.

\section{Disclaimer}

The views and opinions expressed in this article are those of the author and do not necessarily reflect the official policy or position of any affiliated agency of the author.

\section{References}

1. Ritty JM, Solan HA, Cool SJ. Visual and sensory-motor functioning in the classroom: A preliminary report of ergonomic demands. J Am Optom Assoc. 1993;64(4):238-243.

2. Ahn SJ, Legge GE. Printed cards for measuring low vision reading speed. Vis Res. 1995;35(13):1931-1938. https://doi.org/10.1016/0042-6989(94)00293-U

3. Goodrich GL, Kirby J. A comparison of patient reading performance and preference: Optical devices, handheld CCTV (Innoventions Magni-Cam), or stand-mounted CCTV. (Optelec Clearview or RSI Genie). Optometry. 2001;72(8):519-528

4. Wise JC, Sevcik RA, Robin DM, et al. The relationship between different measures of oral reading fluency and reading comprehension in second grade
students who evidence different oral reading fluency difficulties. Am Speech Lang Hear Assoc. 2010;41(3):340-348. https://doi.org/10.1044/0161 Lang Hear Assoc.

5. Wilkins AJ, Jeanes RJ, Pumfrey PD, Laskier M. The Rate of Reading Test: It's reliability and its validity in the assessment of the effects of coloured overlays. Ophthalmic Physiol Opt. 1996;16(6):491-497. https://doi.org/10.1016/0275-5408(96)00028-2

6. Eperjesi F, Fowler CW, Evans, BJW. The effects of coloured light filter overlays on reading rate in age-related macular degeneration. Acta Ophthal Scand. 2004;82(6):695-700. https://doi.org/10.1111/j.1600-0420.2004.00371.x

7. Whittaker SG, Kitchin JL. Visual requirements for reading. Optom Vis Sci. 1993;70(1):54-65. https://doi.org/10.1097/00006324-199301000-00010

8. Lovie-Kitchin JE, Whittaker SG. Prescribing near magnification for low vision patients. Clin Exp Optom. 1999;82(6):214-224. https://doi.org/10.1111/j.1444-0938.1999. tb06651.x

9. Kalloniatis $\mathrm{M}$, Johnston $\mathrm{AW}$. Visual characteristics of low vision children. Optom Vis Sci. 1990;67(1):38-48. https://doi.org/10.1097/00006324-19900100000009

10. Bailey IL, Lovie JE. The design and use of a new near vision chart. Am J Optom Physiol Optics. 1980;57:378-387. https://doi.org/10.1097/00006324-1980060 00-00011

11. Elliott DB, Patel $B$, Whitaker $D$. Development of a reading speed test for potential vision measurements. Invest Ophthalmol Vis Sci. 2001;42(8):1945-1949.

12. Rice ML, Birch EE, Holmes JM. An abbreviated reading speed test. Optom Vis Sci. 2005;82(2):128-133. https://doi.org/10.1097/01.OPX.0000153163.60056.95

13. Makgaba MTN, Oduntan OA. Effects of colored light filter overlays on reading rates in persons with oculo-cutaneous albinism. S Afr Optom. 2008;67:118-124. https://doi.org/10.4102/aveh.v67i3.189

14. Ferraro S, Ferraro J. Chapter 11: Establishing a training instructional program. In: Jose RT, editor. Understanding low vision. New York, NY: American Foundation for the Blind, 1989; p. 251-276.

15. Bland JM, Altman DG. Applying the right statistics: Analyses of measurement studies. Ultrasound Obstetr Gynaecol. 2003;22(1):85-93. https://doi.org/10.1002/uog.122 
16. Abdulkader B, Leat SJ. Reading in children with low vision. J Optom. 2010;3(2):68-73. https://doi.org/10.1016/S1888-4296(10)70010-8

17. Douglas G, Grimley M, Hill E, Long R, Tobin M. The use of Neale Analysis of Reading Ability (NARA) for assessing the reading ability of children with low vision. Br JVis Impair. 2002;20(2):68-75. https://doi.org/10.1177/026461960202 000204

18. Jose RT. Clinical examination of visually impaired individuals. In: Jose RT, editor Understanding low vision. New York, NY: American Foundation for the Blind, 1989; p. 141-185.
19. Bennett AG, Rabbetts RB. Clinical visual optics. 2nd ed. Chapter 3. Oxford: Heinemann-Butterworth, 1995; p. 23-72.

20. Eduardo Paiva C, Marçon Barroso E, Cristina Carneseca E, et al. A critical analysis of test-retest reliability in instrument validation studies of cancer patients under palliative care: A systematic review. BMC Med Res Methodol. 2014;14:2-10. https://doi.org/10.1186/1471-2288-14-8

21. McQuillan J. We don't need no stinkin' exercises: The impact of extended instruction and storybook reading on vocabulary acquisition. Lang Lang Teach. 2019;8:25-35. 